\title{
Choosing a project risk-handling strategy: An analytical model
}

\author{
Miao Fan ${ }^{\mathrm{a}}$, Neng-Pai Lin ${ }^{\mathrm{b}, *}$, Chwen Sheu ${ }^{\mathrm{c}}$ \\ ${ }^{a}$ Department of Marketing and Logistics Management, Chihlee Institute of Technology, Taiwan \\ ${ }^{\mathrm{b}}$ Graduate Institute of Health Care Organization Administration, National Taiwan University, Taipei, Taiwan \\ ${ }^{\mathrm{c} D e p a r t m e n t ~ o f ~ M a n a g e m e n t, ~ K a n s a s ~ S t a t e ~ U n i v e r s i t y, ~ M a n h a t t a n, ~ K S ~ 66506, ~ U S A ~}$
}

Received 1 September 2006; accepted 1 June 2007

Available online 10 July 2007

\begin{abstract}
Project risk management includes the process of risk identification, analysis, and handling (response). Risk handling/ response is the choice of a proper strategy to reduce the likelihood of the occurrence of risk events and/or the magnitude of their negative impact. Research on risk handling is mostly opinion- or case-based and, as such, it offers scant guidelines for making the decision. Managers often choose a risk-handling strategy based on their experience or preference toward risk, with no consideration of project characteristics (e.g., project size, slack, or technical complexity) and the associated financial implications. This study assumes that the choice of the risk-handling strategy should be aligned with unique project characteristics. This study constructed a conceptual framework that defines the relationship between risk-handling strategy and relevant project characteristics. A conceptual model was developed to describe the quantitative relationships among all variables. Accordingly, optimization analysis is performed to derive a minimum-cost risk-handling strategy for a particular risk event. The findings provide insights into how various project characteristics and risk situation affect the choice of a risk-handling strategy.
\end{abstract}

(C) 2007 Elsevier B.V. All rights reserved.

Keywords: Project management; Risk management; Conceptual modeling; Decision making

\section{Introduction}

A project is defined as a series of related activities with a well-defined set of desired end results. Project management is defined as planning, directing, and controlling resources to achieve specific goals and objectives. Most projects are not deterministic since they are subject to risk and uncertainties due to external factors, technical complexity, shifting

\footnotetext{
*Corresponding author.

E-mail addresses: mfan2505@yahoo.com.tw (M. Fan), nengpai@mail2000.com.tw (N.-P. Lin), csheu@ksu.edu (C. Sheu).
}

objectives/scopes, and poor management. The purpose of risk management is to identify risky situations and develop strategies to reduce the probability of occurrence and/or the negative impact of risky events. In practice, project risk management includes the process of risk identification, analysis, and handling (Gray and Larson, 2005). Risk identification requires recognizing and documenting the associated risk. Risk analysis examines each identified risk issue, refines the description of the risk, and assesses the associated impact. Finally, risk handling/response identifies, evaluates, selects, and implements strategies (e.g., insurance, negotiation, reserve, etc.) in order to 
reduce the likelihood of occurrence of risk events and/or lower the negative impact of those risks to an acceptable level. The risk-handling process includes the documentation of which actions should be taken, when they should be taken, who is responsible, and the associated handling costs.

In general, among the three risk-management functions, risk identification and analysis specify and predict the likelihood and the adverse impact of the risks, while risk handling/response is the phase when management could take actions to reduce the probability and/or magnitude of risks. In other words, risk handling plays a proactive role in mitigating the negative impact of project risks (Kerzner, 2006; Miller and Lessard, 2001). Risk handling is achieved by hiring experienced project managers, providing up-front safety training, acquisition of additional information, contracting for missing skills, minimizing project scope changes, etc. In the past, research concentrated more on risk identification and analysis due to their relevance to traditional financial and decision analysis. Despite its importance, risk handling has not received due attention in project risk research. Miller and Lessard (2001) and Royer (2000) contended that the risk-handling decision is frequently made without considering project risk characteristics and environment, which causes irrational management behavior toward managing project risks. This study develops an analytical model that defines the mathematical relationship between project risk parameters and risk event-handling cost. The model should enable managers, at the planning stage of a project, to select a minimum-cost risk-handling strategy for a particular risk event. The next section reviews previous studies pertinent to risk handling.

\section{Literature review}

The literature in project risk handling is limited to opinion-based discussion and case studies that illustrate the applications of various handling strategies. For instance, Anderson (1969) discussed the use of several strategies in reducing risk associated with national defense projects. Baillie (1980) reviewed a number of practical strategies to reduce the risks and uncertainties inherent in $R \& D$ projects. DSMC (1986) reviewed examples of risk handling in weapon development projects, and Tsai (1992) interviewed management in weapon development projects and proposed seven risk-handling strategies. Becker et al. (1999) surveyed more than one hundred companies in the oil and gas industry on the use of various risk-response techniques; however, they did not explain their rationale for selecting particular risk-handling techniques. In order to define risk-response strategies, Royer (2000) discussed the use of brainstorming sessions with clients, project teams, and experts. Finally, the Project Management Body of Knowledge (Project Management Institute, 2004) provided a comprehensive review of various risk-handling strategies. Overall, these studies reviewed and suggested various risk-handling strategies in different types of projects. However, there is no discussion of the dimensions and characteristics of projects that are critical to the choice of handling strategy. It is not clear what variables impact the effectiveness of various handling strategies in different projects, be they $\mathrm{R} \& \mathrm{D}$, construction, or new product development. More specifically, decisions aimed toward aligning handling strategy with unique project characteristics, risks, and external environment have not been addressed.

In practice, the choice of a specific risk-handling strategy is contingent on the risk situation and the project characteristics (Ala-Risku and Karakkainen, 2006; Kwak and Stoddard, 2004; Miller and Lessard, 2001; Royer, 2000; Lefley, 1997; Bromiley and Curley, 1992). For example, management may purchase insurance to buffer against earthquakes, since the occurrence of the risk event cannot be "controlled" and the potential damage could be financially disastrous. In another type of situation, managers may choose to conduct a market survey when additional information might be valuable in reducing the probability of the occurrence of risk events. Only a few studies have attempted to match handling strategy with specific risk situation. March and Shapira (1987) and Wehrung et al. (1988) observed several risk situations (e.g., new product development, overseas market development, production facilities shutdown, and major customer complaints) in the industry and found that the choice of a risk-handling strategy was primarily associated with the management's attitude toward risks and uncertainties. There was no consideration of unique project characteristics and external environment. Flanagan and Norman (1993) developed a framework for deciding on a risk-handling strategy based on the likelihood of occurrence and severity of the risks. Miller and Lessard (2001) used the extent of control over risks to determine the strategy of mitigating project risks. Fan et al. 
(2001), based on case studies of construction projects, suggested that the choice of a risk-handling strategy depended on the extent to which managers were able to affect the probability of the occurrences of risk events. However, it is not clear how management should align risk-handling strategy with unique risk situations and project characteristics.

In summary, previous studies discussed applications of various risk-handling strategies but offered scant guidelines for choosing a strategy that matches the characteristics of projects and risks. Many managers often make risk-handling decisions based on personal attitudes and preference toward risk, which frequently results in irrational behavior patterns (Royer, 2000). Jaafari (2001) suggested that managers should improve risk handling by applying a more holistic approach to evaluating risk-handling decisions and developing quantitative models for integrating and evaluating risk-handling variables. This study develops an analytical model and guidelines that may help managers assess the effectiveness of various risk-handling strategies in minimizing damages associated with risk events. While the final choice of strategy may involve managers' attitudes toward risk, the model provides managers a tool to aid in understanding the financial implications of their decisions. The following section develops a conceptual framework for risk-handling decisions including relevant parameters of the decision. Two risk-handling cost models are established to prescribe the theoretical relationships among those parameters. Optimization analysis of the cost models is then performed to investigate the pattern of selecting risk-handling strategies given specific project environment and characteristics. Finally, the guidelines for making risk-handling decisions are developed and future research is suggested.

\section{Model development}

\subsection{Problem definition}

This study followed previous studies (Royer, 2000; Wehrung et al., 1988) and classified all riskhandling techniques into two categories: risk prevention and risk adaptation. Note the unit of analysis in this project is "risk event", and both techniques require taking actions to mitigate expected loss from risk events. Risk prevention refers to actions taken in the planning stage to reduce the probability of occurrence of risk events by acquiring additional information, improving communication with clients, hiring experienced project managers, choosing more reliable contractors, etc. For example, conducting a market survey could provide more information on new product development and thereby reduce the probability of product failure. In contrast, an adaptation strategy refers to actions implemented in the execution stage. The buffer and reserve required by this strategy are usually planned and prepared for through the project budget and schedule so that managers can reduce the damage/ loss resulting from risk events. In contrast to risk prevention, risk adaptation aims at alleviating and reducing negative impacts resulting from the occurrence of risks. Examples of this strategy include the purchase of insurance to cover for monetary losses, the preparation of a budget reserve, searching for backup suppliers, etc. Under this classification scheme, the research question is defined as follows:

Given specific project characteristics and risk situation, should risk prevention, risk adaptation, or the combination of these two riskhandling strategies be applied to minimize the expected loss associated with a particular risk event?

A conceptual framework is developed next to identify relevant parameters and their relationships with risk-handling decisions.

\subsection{Conceptual framework}

Assume that the probability of the occurrence of event $E$ prior to risk handling is $P_{1}$, and this probability is reduced to $P_{2}$ (the posterior probability) after risk handling, $P_{2} \leqslant P_{1}$. Let $L_{1}$ be the initial total loss from the occurrence of the event, and this loss is reduced to $L_{2}$ after risk handling, $L_{2} \leqslant L_{1}$. The expected loss $\left(R_{1}\right)$ prior to risk handling is $P_{1} \times L_{1}$. Shapira (1998) argued that managers implement risk handling when the current risk level $\left(R_{1}\right)$ is not acceptable. The purpose of project risk handling then is to reduce the level of risk or expected loss from $R_{1}$ to an acceptable level $R_{2}$, where $R_{2}<R_{1}$ and $R_{2}=P_{2} \times L_{2}$. (Table 1 provides the definition of all parameters used in this study.)

Since risk prevention attempts to reduce the probability of the occurrence of risk events, its implementation results in $P_{2}<P_{1}$ and $L_{2}=L_{1}$. Risk adaptation, on the other hand, alleviates losses from the occurrence of risk events, and the implementa- 
Table 1

Description of parameters

$P_{1} \quad$ prior probability of the occurrence of the risk event

$L_{1} \quad$ monetary loss from the risk event

$R_{1} \quad$ expected monetary loss from the risk event $=P_{1} \times L_{1}$

$P_{2}$ posterior probability of the occurrence of the risk event

$L_{2} \quad$ monetary loss from the risk event with risk-handling strategy

$R_{2} \quad$ posterior expected monetary loss from the risk event $=P_{2} \times L_{2}$

$k \quad$ unit risk prevention cost

$\omega$ proportion of uncertainty that cannot be reduced/ controlled under current technology or information, $0 \leqslant \omega \leqslant 1$

$1-\omega$ controllability of project risk

$\beta \quad$ amount of project slack, $\beta \geqslant 0$

$r$ unit opportunity cost or interest rate, $0 \leqslant r \leqslant 1$

$s \quad$ unit crash cost, $s \geqslant 0$

tion of a risk-adaptation strategy results in $P_{2}=P_{1}$ and $L_{2}<L_{1}$. Fig. 1 displays two isoquants, $R_{1}$ and $R_{2}$. Each curve represents numerous combinations of probability $(P)$ and loss $(L)$ that would produce the same level of expected loss $(R=P \times L)$. For example, combinations of various $P_{2}$ and $L_{2}$ on $R_{2}$ (or $A C$ ) curve derive the acceptable risk level $R_{2}$. Theoretically, managers could use alternative riskhandling options to reduce the expected loss from the current level of $R_{1}$ (represented by point $Y$ ) to an acceptable level $R_{2}$. For example, managers could choose a risk-adaptation strategy (indicated by the path $Y A$ ) to reduce the expected loss from the original level $Y\left(P_{1}, L_{1}\right)$ to $A\left(P_{1}, L_{2}\right)$. The probability of the occurrence of project risks remains the same, while the magnitude of loss reduces due to the action taken. Alternatively, managers could take the risk-prevention option (path $Y C$ ) to reduce the likelihood of the occurrence of the risk event to the new level $C\left(P_{2}, L_{1}\right)$. Finally, the third risk-handling option can be the combination of both riskprevention and adaptation strategies (path $Y B$ ) to reduce the expected loss from $Y$ to $B\left(P_{\mathrm{b}}, L_{\mathrm{b}}\right)$, where $P_{2} \leqslant P_{\mathrm{b}} \leqslant P_{1}, L_{2} \leqslant L_{\mathrm{b}} \leqslant L_{1}$. In short, there are three types of risk-handling strategies, $Y A, Y C$, and $Y B$. All three strategies reduce the expected loss to $R_{2}$, but their implementation requires different financial resources and, thus, various levels of total costs. Therefore, the risk-handling decision can be framed as follows: What risk-handling strategy should managers choose in order to reduce the expected loss to an acceptable level at the lowest implementation cost?

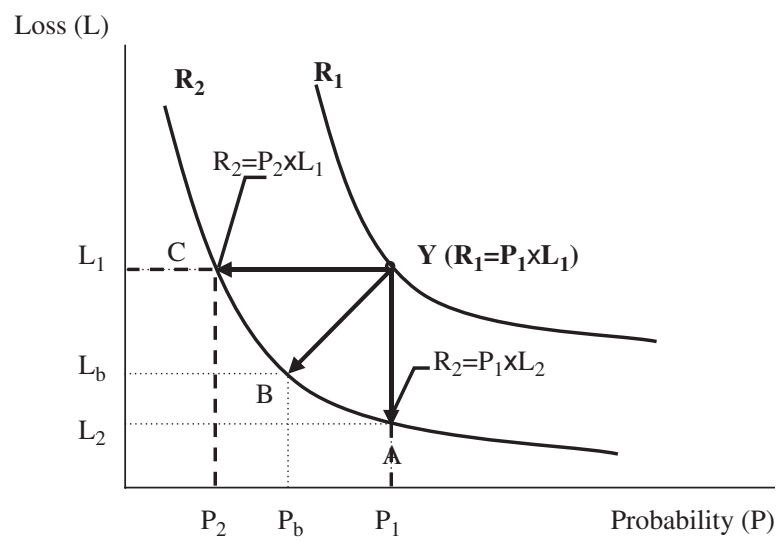

Fig. 1. Risk-handling strategies: prevention, adaptation, and mixed.

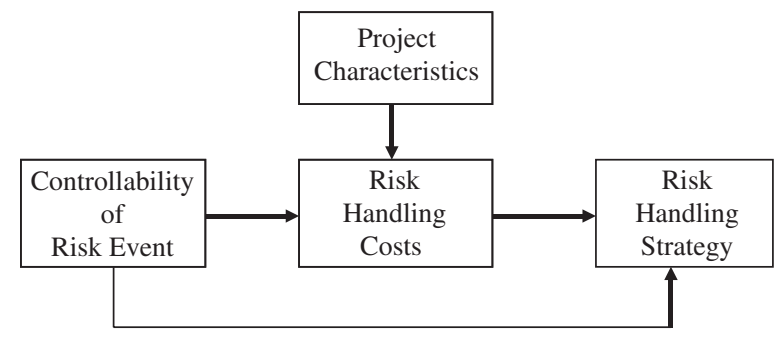

Fig. 2. The conceptual framework.

Fig. 2 is the conceptual framework that illustrates the relationships among several key parameters in the decision of risk handling. This conceptual framework was developed based on the observation from several large-scale construction projects (Fan et al., 2006). Large-scale construction projects are usually involved in enormous budgets over lengthy schedules, and they typically consist of various risk events including natural disasters, technical difficulties, insufficient information, politics, etc. For the purpose of this study, it is necessary to include risk events with a wide range of controllability and multiple events with the same level of controllability across projects. The field study of those construction projects was also used as the base for developing a mathematical model for risk handling in this study. In this conceptual framework, riskhandling strategy is defined as the means and actions taken to reduce the level of risk. In practice, the strategy that managers choose can be risk prevention, risk adaptation, or a combination of these two. This study assumes that the choice of strategy is determined by three parameters: 
controllability of project risk, risk-handling costs, and project characteristics.

First, controllability of risk event refers to the likelihood of changing the probability distribution of the occurrence of the event (Miller and Lessard, 2001). This factor is used to define the nature of the risk situation. A low degree of controllability is often associated with risk events such as natural disasters (e.g., hurricane and earthquake) or economic conditions (e.g., fluctuations of inflation and exchange rates), where little can be done to change the probability of occurrence. In contrast, risk events with a high degree of controllability are often associated with technical, scheduling, and budget problems, which are easier (but not necessarily less expensive) to resolve compared with natural disasters. For example, the risk of receiving a late delivery of components can be reduced by a careful selection of reliable suppliers. Therefore, the level of controllability of project risk could affect the choice of a risk-handling strategy (Gray and Larson, 2005; Miller and Lessard, 2001). Intuitively, managers would adopt a risk-prevention strategy for a project with high levels of controllability, while a riskadaptation strategy is more appropriate for a project with low levels of controllability. Table 2 lists some combinations of level of controllability and probable choice of risk-handling strategy based on observations from several major construction projects and the literature (Fan et al., 2001; Jaafari,
2001; Miller and Lessard, 2001). Many of those handling strategies can be adopted as contractual agreements but the choice of a specific strategy in relation to project characteristics could be challenging. While the choice is clear in the two extreme levels of controllability, the choice becomes less obvious for those risk events involving a medium range of controllability. Specifically, managers can choose either one of the two strategies or the combination to handle risk when the level of controllability is neither extremely high nor low. It is likely that the costs required to handle risk events would ultimately determine the choice of a specific handling strategy in a "non-extreme" situation.

Project characteristics include project size, technological complexity, level of schedule slack, and external economic and political factors. Those characteristics could affect the cost of different actions and, in turn, affect the choice of handling strategy. For example, collecting information and surveying the reliability of contractors improve the selection decision and is a possible option to reduce the likelihood of late completion, but the cost of a survey is likely to be higher in a more technically complicated project. In addition, a project with more slack time is more capable of buffering against schedule delay due to risk events. Politics also plays a major role in project risk (Al-Tabtabai and Alex, 2000). A nuclear plant construction project is likely to involve government regulations and environmen-

Table 2

Project risk controllability and risk-handling strategy

\begin{tabular}{|c|c|c|c|}
\hline Risk event & Controllability & Specific risk-handling actions & $\begin{array}{l}\text { Type of risk- } \\
\text { handling strategy }\end{array}$ \\
\hline $\begin{array}{l}\text { Acts of God: earthquake, flood, } \\
\text { hurricane, etc. }\end{array}$ & Low & Purchase insurance coverage & Risk adaptation \\
\hline Fluctuations of exchange rate & Low & Prepare contingency fund & Risk adaptation \\
\hline Occurrence of inflation & Low & Prepare reserve & Risk adaptation \\
\hline $\begin{array}{l}\text { Acquisition of land that involves } \\
\text { relocating residents }\end{array}$ & Medium & $\begin{array}{l}\text { Provide residents with substantial } \\
\text { subsidies }\end{array}$ & Risk adaptation \\
\hline $\begin{array}{l}\text { Failure of on-time completion by } \\
\text { subcontractors }\end{array}$ & Medium & $\begin{array}{l}\text { - Perform more strict subcontractor } \\
\text { selection } \\
\text { - Select a second contractor }\end{array}$ & $\begin{array}{l}\text { - Risk prevention } \\
\text { - Risk adaptation }\end{array}$ \\
\hline $\begin{array}{l}\text { Alternation of project specifications/ } \\
\text { scope }\end{array}$ & Medium & $\begin{array}{l}\text { - Enhance control and communication } \\
\text { - Set up contingency plan and provide } \\
\text { design flexibility }\end{array}$ & $\begin{array}{l}\text { - Risk prevention } \\
\text { - Risk adaptation }\end{array}$ \\
\hline Underground barriers & High & $\begin{array}{l}\text { Conduct more thorough underground } \\
\text { investigation }\end{array}$ & Risk prevention \\
\hline $\begin{array}{l}\text { Integration of entire mass transportation } \\
\text { systems }\end{array}$ & High & Subcontract to one single bidder & Risk prevention \\
\hline
\end{tabular}


tal policies, which require more communication among various parties and, therefore, results in higher risk-handling costs. In general, depending on the characteristics of a project, a specific riskhandling strategy involves different amounts of handling costs.

Risk-handling cost is defined as the expenses incurred in implementing a selected strategy that would reduce risks to an acceptable level. This study assumes that handling costs are a function of the controllability of risk and project characteristics. Fig. 2 shows that controllability affects the selection of handling strategy in two ways. Low controllability implies higher handling costs but for a risk event with high controllability it may still be too expensive to prevent its occurrence. Moreover, extremely high or low controllability usually implies the application of a prevention or adaptation strategy (see Table 2). Consequently, given a particular risk event, a risk-handling strategy, be it prevention, adaptation, or mixed, is chosen based on the controllability of the event as well as the associated handling cost. Specifically, managers favor a handling strategy with a lower implementation cost, and the decision is also made considering the level of controllability.

Note that utility theory would suggest that managers will take the output of the model in Fig. 2 and make their final decision by incorporating the decision-maker's attitude toward risk (Holloway, 1979). In other words, managers will compare the cost of the cheapest handling strategy (the output of this model) with the reduction of expected loss. In a situation where the cost outweighs the benefit, a risk taker will choose not to take any action, while a risk averter may still choose to implement a handling strategy. The remainder of this section provides mathematical definitions of project characteristics, controllability, and handling costs. Accordingly, this study develops a mathematical model that would determine a minimum-cost handling strategy.

\subsection{Risk-handling cost model}

Since a risk-handling strategy involves the possible application of risk prevention and/or risk adaptation, the total risk event-handling cost (TC) is, therefore, the sum of the two types of cost, risk-prevention cost $\left(C_{\mathrm{P}}\right)$ and risk-adaptation $\operatorname{cost}\left(C_{\mathrm{L}}\right)$.

\subsubsection{Risk-prevention cost $\left(C_{p}\right)$ function}

Recall that the purpose of risk handling is to reduce the level of risk or expected loss from $R_{1}$ to $R_{2}$, where $R_{2}<R_{1}$ and $R_{2}=P_{2} \times L_{2}$. The implementation of a risk-prevention strategy results in $P_{2}<P_{1}$ and $L_{2}=L_{1}$. Prevention cost $\left(C_{\mathrm{p}}\right)$ is a function of $P_{2}$ with the following properties and assumptions:

- $C_{\mathrm{p}}$ increases with the decrease of $P_{2}$. It costs to reduce the probability of the occurrence of a risk event.

- When $P_{2}=P_{1}, C_{\mathrm{p}}=0$. No handling cost is incurred when the prior probability is equal to the posterior probability.

- $\mathrm{MC}_{\mathrm{p}}$ represents the marginal prevention cost, or the slope of $C_{\mathrm{p}} . \mathrm{MC}_{\mathrm{p}}$ is negative due to the inverse relationship between $C_{\mathrm{p}}$ and $P_{2}$. As $P_{2}$ approaches a small value (the posterior probability of occurrence of the event becomes extremely small), the marginal cost becomes extremely large, or $\mathrm{MC}_{\mathrm{p}}$ approaches $\infty$. In other words, it becomes more expensive to reduce the probability of occurrence further when the probability is already low.

- $k$ represents unit prevention cost where $k>0$. $k$ is a measure of the difficulty or complexity of reducing risks by either obtaining additional information or overcoming technical and political obstacles. For a given $P_{1}$ and $P_{2}$, a larger $k$ is related to a larger $C_{\mathrm{p}}$ and a smaller $\mathrm{MC}_{\mathrm{p}}$ (or larger absolute value of $\mathrm{MC}_{\mathrm{p}}$ ).

$C_{\mathrm{p}}$ is also related to the level of controllability of project risks, $1-\omega$, where $\omega$ is the proportion of uncertainty that cannot be reduced/controlled using current technology or information and $0 \leqslant \omega \leqslant 1$. Fig. 3 illustrates the concept of $1-\omega$ and $\omega$. The

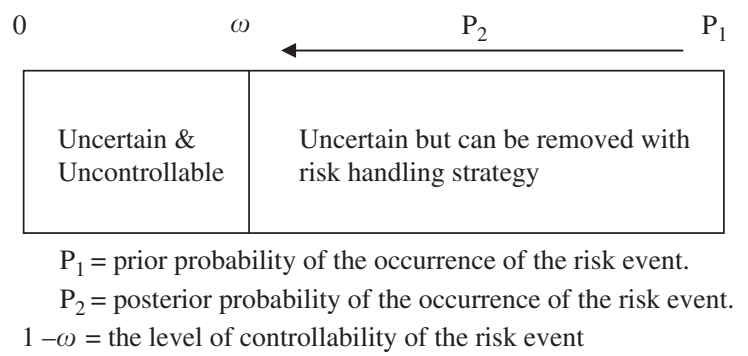

Fig. 3. Level of controllability, $P_{1}=$ prior probability of the occurrence of the risk event. $P_{2}=$ posterior probability of the occurrence of the risk event. $1-\omega=$ the level of controllability of the risk event. 
proportion $P_{1}-\omega$ is the amount of project uncertainty that can be feasibly removed, while $P_{2}-\omega$ represents the amount of uncertainty that is technically removable but is not removed with a specific handling strategy. A large value of $\omega$ implies a low degree of controllability and, thus, a high value of $\mathrm{MC}_{\mathrm{p}}$. Overall, $\mathrm{MC}_{\mathrm{p}}$ can be defined as a function of $P_{2}, \omega$, and $k$ :

$\mathrm{MC}_{\mathrm{p}}=\frac{-k}{\left(P_{2}-\omega\right)}$.

The risk-prevention cost, $C_{\mathrm{p}}$, then is the integral of $\mathrm{MC}_{\mathrm{p}}$ from $P_{1}$ to $P_{2}$, or

$C_{\mathrm{p}}=\int_{P_{1}}^{P_{2}} \mathrm{MC}_{\mathrm{p}} \mathrm{d} P_{2}=\int_{P_{1}}^{P_{2}} \frac{-k}{\left(P_{2}-\omega\right)} \mathrm{d} P_{2}=k \ln \left(\frac{P_{1}-\omega}{P_{2}-\omega}\right)$.

\subsubsection{Risk-adaptation cost $\left(C_{L}\right)$ function}

A risk-adaptation strategy intends to reduce loss resulting from risks. There are two types of loss, monetary loss $(m)$ and schedule delay loss $(t)$. In the case of monetary loss, the purpose of risk adaptation is to maintain a "buffer" to absorb the whole or partial loss associated with risk events. The buffer approach is similar to the concept of "organizational slack" with the purpose of increasing the effectiveness of adapting to external environmental uncertainties (Bourgeois, 1981; Gray and Larson, 2005). The risk-adaptation cost is treated as the opportunity cost associated with the provision of such a buffer. For instance, when insurance is used as a risk-adaptation strategy, the associated premium is the adaptation cost, and the insurance coverage is the buffer prepared to deal with the potential loss. Alternatively, we can establish a management reserve to reduce the impact of risk events (Gray and Larson, 2005). The literature suggests a linear relationship between the opportunity cost and the amount of potential loss, and rate of investment can be used as the estimation of $C_{\mathrm{L}}$ (Baumol, 1977).

In the case of loss due to schedule delay, the adaptation cost is estimated based on the concept of slack $(\beta)$ (Stigler, 1961; de Vonder et al., 2005). Depending on the amount of slack in the project, the cost of establishing a time buffer varies. This concept is similar to project compression where the unit crash cost increases as the degree of crash intensifies (Kerzner, 2006). In other words, the handling (crash) cost increases exponentially with a decrease in slack. The risk-adaptation cost $\left(C_{\mathrm{L}}\right)$ has the following properties and assumptions:

(1) $C_{\mathrm{L}}$ increases with the decrease of $L_{2}$.

(2) When $L_{2}=L_{1}, C_{\mathrm{L}}=0$.

(3) In the case of monetary loss, the marginal adaptation cost $\left(\mathrm{MC}_{\mathrm{L}}\right)$ is a constant $r$, the rate of return on investment or insurance premium. The risk-adaptation cost $\left(C_{\mathrm{L}}\right)$ function is

$$
C_{\mathrm{L}}=r\left(L_{1}-L_{2}\right) \text {. }
$$

(4) In the case of time delay loss, the marginal cost of compressing a project schedule is lower when there is more slack time in the project. Assuming that $s$ is the unit crash cost and that it increases exponentially with the decrease of $\beta$ (the amount of slack), $\beta \geqslant 0$. The marginal cost function is

$\mathrm{MC}_{\mathrm{L}}=-s \mathrm{e}^{-\beta L_{2}}, s>0$.

When $L_{2}=0, \mathrm{MC}_{\mathrm{L}}=-s$, which indicates that $s$, the absolute value of $\mathrm{MC}_{\mathrm{L}}$, is the marginal cost to absorb the last unit of possible time delay. $\beta$ is the amount of slack in the project and the less er the slack the higher the crash cost ( $s$ and $\left.\left|\mathrm{MC}_{\mathrm{L}}\right|\right)$. Therefore, the risk-adaptation cost function for time delay loss can be defined as $C_{\mathrm{L}}=\int_{L_{1}}^{L_{2}} \mathrm{MC}_{\mathrm{L}} \mathrm{d} L_{2}=$ $\int_{L_{1}}^{L_{2}}-s \mathrm{e}^{-\beta \ell} \mathrm{d} L_{2}$ and

$C_{\mathrm{L}}=\frac{s}{\beta}\left(\mathrm{e}^{-\beta L_{2}}-\mathrm{e}^{-\beta L_{1}}\right)$.

\subsubsection{Risk-handling cost (TC)}

Given any particular risk event, its risk-handling cost (TC) includes risk-prevention and risk-adaptation costs or $\mathrm{TC}\left(P_{2}, L_{2}\right)=C_{\mathrm{P}}+C_{\mathrm{L}}$. This study assumes that risk events result in one of the two losses, monetary or schedule. Therefore, with the prevention cost function (Eq. (2)) and two adaptation cost functions (Eqs. (5) and (7)), we generated two TC functions as follows:

$$
\begin{aligned}
& \mathrm{TC}_{1}=k \ln \left(\frac{P_{1}-\omega}{P_{2}-\omega}\right)+r\left(L_{1}-L_{2}\right), \\
& \mathrm{TC}_{2}=k \ln \left(\frac{P_{1}-\omega}{P_{2}-\omega}\right)+\frac{s}{\beta}\left(\mathrm{e}^{-\beta L_{2}}-\mathrm{e}^{-\beta L_{1}}\right) .
\end{aligned}
$$

These two cost functions are then used to perform an optimization analysis to identify the optimal level of $P_{2}$ and the minimum-cost handling strategy given the specific sets of risk situation $(\omega)$, project characteristics, and handling costs $(k, r, s, \beta)$, and the desired risk level $\left(R_{2}\right)$. 


\section{Optimization analysis}

The primary purpose of this study is to identify an optimal strategy to reduce project risk from the current level $R_{1}$ to an acceptable $R_{2}$ with minimum cost as indicated by the following model:

Min $\mathrm{TC}\left(P_{2}, L_{2}\right)$

s.t. $\quad P_{2} \times L_{2}=R_{2}$.

Let $p=P_{2}, l=\mathrm{L}_{2}, \mu=R_{2} / R_{1}$, and $0 \leqslant \mu \leqslant 1$. The above model can be rewritten as

Min $\mathrm{TC}(p, l)$

s.t. $\quad p l=m R_{1}$

$0 \leqslant p \leqslant P_{1} ; 0 \leqslant l \leqslant L_{1} ; 0 \leqslant \mu \leqslant 1$.

Since $l=\mu R_{1} / p$, TC $(p, l)=\mathrm{TC}\left(p, \mu R_{1} / p\right)$. Therefore, TC can be regarded as the function of $p$ and $\mu P_{1} \leqslant p \leqslant P_{1}$. Mathematically, we can take the first and second derivative of TC $\left(p, \mu R_{2} / p\right)$ to find the "optimal" acceptable risk level $p^{*}$ that would minimize the risk event-handling cost in the restricted domain $\left[\mu P_{1}, P_{1}\right]$. Note that $p^{*}$ is associated with the optimal combination of parameters $(\omega, r$ (or $s), \beta$ and $k$ ) that would provide the lowest cost to reach $R_{2}$. As illustrated in Fig. 1, we can classify various risk-handling strategies into three categories:

(1) Risk prevention $(Y C)$, where $p^{*} \sim \mu P_{1}$.

(2) Risk adaptation $(Y A)$, where $p^{*} \sim P_{1}$.

(3) Mixed strategy $(Y B)$, where $\mu P_{1}<p^{*}<P_{1}$.

The process and result of the cost optimization analysis for those two cost functions (Eqs. (8) and (9)) are presented in Appendix A. Table 3 summarizes the findings of the analysis. In short, the values of $\omega$ and $r R_{2} / k$ (or $s R_{2} / k$ in the case of $\mathrm{TC}_{2}$ ) determine the optimal $p$ value $\left(p^{*}\right)$. A high $r R_{2} / k$ value implies high opportunity cost (large $r$ ), large project scale $\left(R_{2}\right)$, or a low prevention cost (small $k$ ). When $r R_{2} / k$ is large, $p^{*}$ approaches the lower bound of the solution domain $\mu P_{1}$, implying the selection of a prevention strategy. On the other hand, when $r R_{2} / k$ is small, $p^{*}$ approaches the upper bound of the solution range, $P_{1}$, or $p^{*}=P_{1}$, which implies the selection of an adaptation strategy. Nonetheless, the effect of $r R_{2} / k$ on the location of $p^{*}$ is also affected by the value of $\omega$. When $\omega$ is extremely large (extremely low controllability), $p^{*}$ always equals $P_{1}$ regardless of the value of $r R_{2} / k$. As $\omega$ decreases, $p^{*}$ shifts from the upper bound $\left(P_{1}\right)$ to the middle of
Table 3

Results of optimality analysis

Cost function Results

$\mathrm{TC}_{1} \quad 1 . r R_{2} / k \leqslant 4 \omega$

(Monetary)

The optimum solution locates at right extreme of $\left[\mu P_{1}, P_{1}\right]$, or $P_{1}$, which implies the selection of a risk-adaptation strategy.

2. $r R_{2}>4 k \omega$

(a) When $\omega$ is extremely large (extremely low controllability), $p^{*}=P_{1}$ regardless of the value of $r R_{2} / k$, i.e., adaptation strategy is chosen.

(b) As $\omega$ decreases, $p^{*}$ can be found between $\mu P_{1}$ and $P_{1}$ but not at the two extremes, which implies a mixed strategy. As $\omega$ decreases even more (controllability increases), $r R_{2} / k$ begins to have more impact on the value of $p^{*}$. A large $r R_{2} / k$ moves $p^{*}$ toward $\mu P_{1}$ (prevention), and a small $r R_{2} / k$ pushes $p^{*}$ toward $P_{1}$ (adaptation).

$\mathrm{TC}_{2}$ (Time 1 . When $\beta$ approaches $0, \mathrm{TC}_{2} \sim \mathrm{TC}_{1}$.

delay)

2. When $\beta$ is greater than a threshold value, $p^{*}$ approaches upper bound $P_{1}$.

the domain $\left(\mu P_{1}<p^{*}<P_{1}\right)$ and finally to the lower bound $\left(\mu P_{1}\right)$. Such movement of $p^{*}$ implies switching from an adaptation to a mixed and then to a prevention strategy. This result is consistent with the previous observations presented in Table 2 . When $\omega$ is not extremely large, $r R_{2} / k$ has greater impact on the value of $p^{*}$. A large $r R_{2} / k$ pushes $p^{*}$ toward $\mu P_{1}$ (prevention), while a small $r R_{2} / k$ moves $p^{*}$ toward $P_{1}$ (adaptation). The remainder of this section discusses the managerial implications of the effects of $\omega$ and $r R_{2} / k$ on $p^{*}$, or the selection of a project risk-handling strategy.

\subsection{The value of controllability $(1-\omega)$}

When $\omega$ (the level of uncertain and uncontrollable proportion) has a large value (i.e., $1-\omega$ is small and the degree of controllability is low), its effect on the choice of risk-handling strategy dominates that of other parameters $\left(r, s, k, R_{2}\right)$. For example, it is unlikely that managers are able to do anything to reduce the probability of the occurrence of acts of God. Therefore, the likely strategy to be implemented is risk adaptation, such as purchasing insurance coverage to reduce the negative impact of risk events. As $\omega$ begins to 
decrease (project controllability increases), prevention or a combination of the two strategies becomes more probable. Various project characteristics $\left(r R_{2}\right)$ $k$ or $\left.s R_{2} / k\right)$ are then assessed to determine a minimum-cost risk-handling strategy.

\subsection{The value of $r R_{2} / k$ (or $s R_{2} / k$ )}

Note that the term $r R_{2} / k$ (or $s R_{2} / k$ ) represents the project characteristics in terms of project size, complexity, financial, and project slack situations. Table 4 summarizes the practical implications of these parameters using examples from several construction projects. First, $k$ is the unit cost of reducing the probability of the occurrence of risk events, which is a surrogate of the difficulty of reducing risks by obtaining additional information or the complexity of overcoming technical obstacles. A larger $k$ value indicates a higher cost of risk prevention, which encourages the selection of a riskadaptation strategy. Next, $r$ (or $s$ ) represents the cost of creating a monetary (or time) buffer for risk uncertainty. A small value of $r$ (or $s$ ) (e.g., insurance premium, monetary reserve, and crashing cost) is

Table 4

Parameters of project characteristics

\begin{tabular}{|c|c|c|}
\hline Project characteristics & Implications & Parameter \\
\hline \multirow{2}{*}{$\begin{array}{l}\text { 1. High level of technological } \\
\text { complexity involved in the } \\
\text { project }\end{array}$} & $\begin{array}{l}\text { Difficult to obtain } \\
\text { information }\end{array}$ & $\begin{array}{l}\text { Large } k \\
\text { value }\end{array}$ \\
\hline & $\begin{array}{l}\text { Difficult to handle } \\
\text { obstacles } \\
\text { encountered }\end{array}$ & \\
\hline $\begin{array}{l}\text { 2. High level of involvement by } \\
\text { various parties }\end{array}$ & $\begin{array}{l}\text { Difficult to } \\
\text { communicate or } \\
\text { resolve conflicts }\end{array}$ & $\begin{array}{l}\text { Large } k \\
\text { value }\end{array}$ \\
\hline $\begin{array}{l}\text { 3. Weak technical background } \\
\text { or lack of expertise and } \\
\text { experience in project team }\end{array}$ & $\begin{array}{l}\text { Difficult to deal with } \\
\text { unexpected events }\end{array}$ & $\begin{array}{l}\text { Large } k \\
\text { value }\end{array}$ \\
\hline $\begin{array}{l}\text { 4. Companies are undertaking } \\
\text { many similar projects } \\
\text { simultaneously }\end{array}$ & $\begin{array}{l}\text { Tight financial } \\
\text { situation }\end{array}$ & $\begin{array}{l}\text { Large } r \\
\text { value }\end{array}$ \\
\hline \multirow{2}{*}{$\begin{array}{l}\text { 5. Benign environment with } \\
\text { little political interference, } \\
\text { flexible regulations and } \\
\text { favorable economy }\end{array}$} & $\begin{array}{l}\text { More project } \\
\text { execution flexibility }\end{array}$ & $\begin{array}{l}\text { Low } r \text { and } \\
s \text { values }\end{array}$ \\
\hline & $\begin{array}{l}\text { More financial } \\
\text { resources and time } \\
\text { buffers }\end{array}$ & \\
\hline 6. Tight project schedule & Little time slack & $\begin{array}{l}\text { Large } s \\
\text { value }\end{array}$ \\
\hline 7. Large project scale & $\begin{array}{l}\text { High expected project } \\
\text { risk loss }\end{array}$ & $\begin{array}{l}\text { Large } R_{2} \\
\text { value }\end{array}$ \\
\hline
\end{tabular}

equivalent to a low adaptation cost. Finally, $R_{2}$ represents the acceptable expected loss by decisionmakers. Managers who are risk-seekers may be willing to set a relatively high $R_{2}$ level, while riskaverters will choose a lower $R_{2}$ level. Moreover, the value of $R_{2}$ is likely to be associated with the size of projects as well. The expected loss on large-scale projects is high and managers would accept a larger $R_{2}$ than on small projects. Thus, managers are more inclined to choose a risk-prevention strategy to reduce the damage of risk events when the project scale and the expected loss are large.

Overall, a high $r R_{2} / k$ value implies a relatively high adaptation cost and the preference of a prevention strategy. When there is a high crashing cost (large $s$ ), a high opportunity cost (large $r$ ), a large project scale $\left(R_{2}\right)$, or a low prevention cost (small $k$ ), $r R_{2} / k$ is large and risk prevention is a more economical option. In contrast, a riskadaptation strategy is associated with low crashing cost, low opportunity cost, small project scale, and high prevention cost. Fig. 4 displays the general pattern of risk-handling decisions with regard to the values of $r R_{2} / k$ and $\omega$. A risk-prevention strategy is chosen (see zone 1) with large values of $r R_{2} / k$ and small $\omega$, which represents a combination of high controllability, high crashing cost (large $s$ ), high opportunity cost (large $r$ ), large project scale $\left(R_{2}\right)$, or low prevention cost (small $k$ ). If controllability is low, prevention cost is very high, and crashing and opportunity costs are low (see zone 3), a riskadaptation strategy is selected. Moreover, when the level of controllability is extremely low, the effect of project characteristics becomes less significant, and

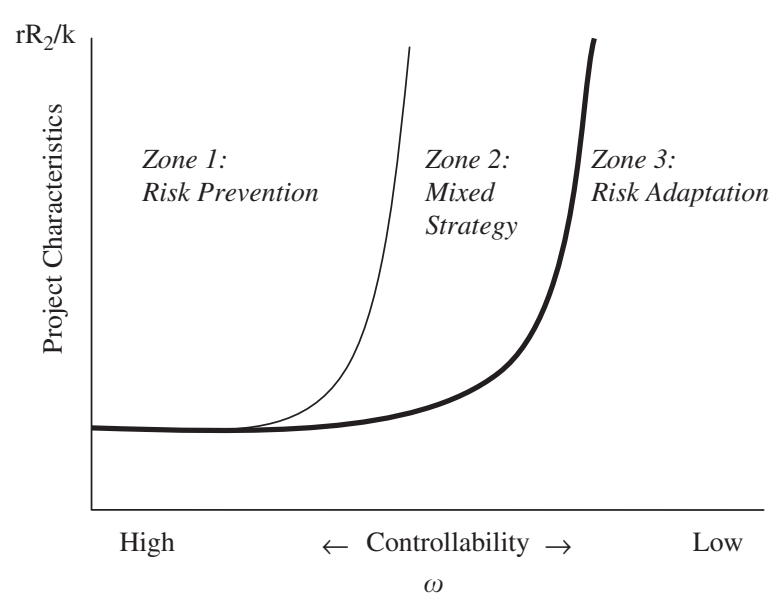

Fig. 4. Choice of risk-handling strategy (*zones can be defined using Eqs. (A1) and (A2) in Appendix A). 
a risk-adaptation strategy is always preferred. Managers are more likely to purchase insurance to buffer potential loss against catastrophes such as earthquakes and floods. Finally, in the situation where the controllability of the project is not clear (i.e., is not at either extreme; see zone 2), the mixed strategy could be adopted to minimize the total handling cost.

The result of the optimization analysis of $\mathrm{TC}_{2}$ also indicates that an adaptation strategy is preferred when there is a high level of slack $(\beta)$ available.

\section{Numerical example}

The purpose of this section is to exemplify how the mathematical model (Eq. (8)) and the decision model (Fig. 4) could enable managers with riskhandling decision-making. As both the mathematical and the decision models indicate, managers need three parameters, $R_{2}, k$, and $r$, to select an optimal handling strategy. We use the "underground barrier" risk event in Table 2 as an example to illustrate the application of the proposed models. Suppose the a priori probability of damaging underground cables $\left(P_{1}\right)$ is 0.5 , and the cost to remove the barriers and compensate for the damage is $\$ 100,000$, the expected loss $\left(R_{1}\right)$ would be $\$ 50,000$ or $0.5 \times \$ 100,000$. If managers intend to reduce the expected loss by $50 \%$ to achieve a targeted level of $R_{2}=\$ 25,000$, the following three options are available.

\subsection{Prevention strategy ( YC in Fig. 1)}

Since $P_{2}=P_{1} \times 0.5=0.25$ and $L_{2}=L_{1}$, the total risk-handling cost can be computed using Eq. (8).

$\mathrm{TC}($ prevention $)=k \ln \left(\frac{0.5-0}{0.25-0}\right)+r(0)=0.7 k$.

Note that the $k$ value represents the cost of obtaining additional information to reduce the level of uncertainty, and it can be estimated indirectly in practice. In this example, reducing the probability of encountering underground barriers to $25 \%$ can be achieved through gathering additional information such as the map of the current underground cable or water pipe network. The cost involved would be the fee of acquiring the cable/pipe network information from the city government and any associated administration cost. In reality, gathering such information would not be huge. Suppose the cost is $\$ 500$, then the total handling cost of the prevention strategy would be $0.7(\$ 500)$ or $\$ 350$.

\subsection{Adaptation strategy ( $Y A$ in Fig. 1)}

With an adaptation strategy, $P_{2}=P_{1}=0.5$ and $L_{2}$ is reduced from the original level $\left(L_{1}=\$ 100,000\right)$ to $\$ 50,000$ (or $\$ 25,000 / 0.5$ ) in order to reach the targeted $R_{2}$ level. Therefore, the total risk-handling cost is

$\mathrm{TC}($ adaptation $)=k \ln (1)+r(100,000-50,000)=50,000 r$.

Managers can provide contingent reserve or purchase insurance to reduce the expected loss to $L_{2}=\$ 50,000$. The cost of both options is related to the opportunity cost of the premium rate. While the exact insurance fee may depend on the nature of the construction and the technical complexity of operations, such information is available in reality. A rate of $1 \%$ would result in the handling cost of $\mathrm{TC}=50,000(0.01)$ or $\$ 500$.

\subsection{Mixed strategy ( $Y B$ in Fig. 1)}

Under this strategy, the manager can find various combinations of $P_{2}$ and $L_{2}$ that would result in the targeted level of $R_{2}, \$ 25,000$. Taking the pair of $P_{2}=0.4$ and $L_{2}=\$ 62,500$ as an example, we can compute the upper bound of the handling cost assuming that $k$ and $r$ remain the same.

$\mathrm{TC}=500 \ln (0.5 . / 0.4)+0.01(100,000-62,500)=\$ 485$.

Consequently, the prevention strategy has the lowest cost (\$350) to achieve the lower level of expected loss $\left(R_{2}=\$ 25,000\right)$.

Continuing with this numerical example, we can further illustrate the practical relevance of the decision model in Fig. 4 by analyzing the interactions between $R_{2}, k$, and $r$. If managers attempt to achieve an even lower $R_{2}$ level such as $\# 5000$, then the total cost for the three options with the same $k$ and $r$ values are $\$ 1151$ (prevention), $\$ 900$ (adaptation), and $\$ 1208$ (mixed), respectively. Therefore, adaptation becomes the most economical riskhandling strategy. This finding is consistent with the behavior of the decision model in Fig. 4, where an adaptation strategy becomes more attractive when $R_{2}$ becomes small. Alternatively, if it requires both cable network information and further underground investigation to reduce the probability of damaging underground cable networks, the value of 
$k$ increases and both the cost model and the decision model would indicate the preference of adaptation strategy.

Finally, assuming that the construction project is technically complex and the insurance fee or the cost providing contingent reserve is high, the opportunity cost could increase to $4 \%$. Keeping $R_{2}$ and $k$ unchanged, the total cost of the three handling strategies becomes $\$ 1151$ (prevention), $\$ 3600$ (adaptation), and \$3458 (mixed), respectively. Therefore, the manager could select prevention as the best risk-handling strategy, which is again consistent with the suggestion from the decision model in Fig. 4. What is worth noting is the feasibility of estimating the values of those parameters in practice.

In summary, this numerical example is used to demonstrate the practical relevance of the proposed cost model and the decision model in Fig. 4. Note that PMI (2004) also offers the following suggestions for assessing risk-related parameters.

Risk can be assessed in interviews or meetings with participants selected for their familiarity with risk categories on the agenda. Project team members and, perhaps, knowledgeable persons from outside the project, are included. Expert judgment is required, since there may be little information on risks from the organization's database of past projects." (Project Management Body of Knowledge, 2004, p. 251)

Namely, if the parameters are not readily available, expert judgment can be a reliable source for assessing their values.

\section{Conclusions}

Despite its importance to the success of project management, risk management is rarely approached with the same rigor as other project management processes such as project scope and scheduling. The lack of a systematic approach in making the riskhandling decision has contributed to irrational behavior patterns managers exhibit to fend off the impact of project risks (Royer, 2000). It is suggested that the development of quantitative models for integrating and evaluating risk-handling variables is necessary to improve risk handling and, therefore, risk management (Stewart and Fortune, 1995).

This study establishes a conceptual framework for risk-handling decisions, which defines relationships among risk-handling strategy, project char- acteristics (project size, slack, unit prevention cost), and risk situation (level of risk controllability). We developed a mathematical model of risk-handling (prevention and adaptation) costs and performed an optimality analysis to determine the minimum-cost strategy. The primary purpose is to enable managers, at the planning stage of a project, to quantify relevant parameters, to rationalize and analyze alternatives, and to select a particular risk-handling strategy that could minimize handling cost for a particular risk event. Theoretically, this study contributes to the development of the conceptual framework of risk-handling decisions (with identification of important project risk parameters), riskhandling cost models, and the relationship between the optimal handling strategy and project characteristics and risk situation. Managerially, we provided guidelines for selecting a minimum-cost riskhandling strategy that would reduce the risk of an event to an acceptable level, given a set of project characteristics and risk situation. No longer will managers make a risk-handling decision based simply on their attitude toward risks without considering unique project characteristics, risk situation, and cost implications. The following is a summary of the guidelines developed:

(1) When the complexity of a project (defined as ease of conducting internal and external communication among parties, obtaining necessary information, keeping project specifications/ scope intact, etc.) is low and the unit prevention cost is low, a risk-prevention strategy is preferred.

(2) When the project team has strong management skills (e.g., complete information network, strong project experience and ability), the ability to reduce the prior probability of risk is high. Therefore, the unit prevention cost is likely to be low, and a risk-prevention strategy gives lower cost.

(3) For a specific risk event, the larger the project scale, the more likely risk a prevention strategy will be adopted to minimize total cost.

(4) When financial resources are sufficient and the likelihood of increasing project budget is high, the unit cost of monetary reserve is low, and thus a risk-adaptation strategy is preferred.

(5) For projects with little slack and high pressure for on-time completion, the unit cost of crash is high, and a risk-prevention strategy is preferred. 
A few issues may limit the generalization of the results. First, all the project characteristics $\left(R_{2}, r, s\right.$, and $k$ ) in the risk-handling cost models were identified, analyzed, and discussed based on observations from a few major construction projects and previous project management literature. While the literature supported the selection of those parameters in defining project characteristics, it is not clear whether any other critical parameters were missed in the analysis. Practitioners have suggested managing different types of projects differently. While all cost models were developed without assuming a specific type of project, the effects of parameters in other types of projects, such as $R \& D$, need further study. Case studies in other industries are necessary to confirm the significance of those parameters to the decision of risk handling. Future research must collect empirical data to confirm the significance of those parameters and to verify the proposed framework and the cost model.

Another limitation of this study is related to the estimation of model parameters. The values for most of the parameters in risk management are derived from estimation (Project Management Institute, 2004). Nonetheless, Pender (2001) and Zahir et al. (2002) suggested that traditional use of the probability theory is insufficient to estimate the values of risk-management parameters, and the theory of fuzzy set should be applied to produce the estimation. In reality, quantifying the variable controllability would not be a trivial task. We suggest that the estimate of controllability be made based on $P_{1}$ and $P_{2}$, the prior and posterior probability of the occurrence of the risk event. Both $P_{1}$ and $P_{2}$ have been used in project riskmanagement research, and the difference of those two values would be an estimate of controllability. Considering the importance of including the concept of controllability as suggested by the literature, future studies should investigate the estimation of this variable.

Finally, it is worthy of note that the decision framework in Fig. 2 can be extended by including the comparison of the best cost of risk-handling strategy and the reduction of reduced expected loss. With such cost-benefit comparisons, the final riskhandling decision will be made based on a manager's utility function, or the attitude toward risk (Holloway, 1979). In this case, the proposed framework in Fig. 2 and the cost analysis provide valuable quantitative information for making the risk-handling decision based on utility theory.

\section{Appendix A. Optimization analysis}

\section{A.1. Optimization analysis for $T C_{1}$}

Substitute $l=R_{2} / p$ to Eq. (8) and

$\mathrm{TC} 1=k \ln \left(\frac{P_{1}-\omega}{P_{2}-\omega}\right)+r\left(L_{1}-L_{2}\right)$.

To minimize the level of $\mathrm{TC}_{1}$ within the close domain $\left[\mu P_{1}, P_{1}\right]$ we can take the derivative of $\mathrm{TC}_{1}$ with respect to $p$.

$\mathrm{dTC}_{1}=\frac{-k}{p-\omega}+\frac{r R_{2}}{p^{2}}=\frac{-k p^{2}+r R_{2} p-r R_{2} \omega}{p^{2}(p-\omega)}$.

The determinate coefficient of $-k p^{2}+r R_{2} p-$ $r R_{2} \omega$ is $r R_{2}-4 k \omega$. Given the value of $r R_{2}-4 k \omega$, $\mathrm{TC}_{1}$ can be solved as

1. $r R_{2}-4 k \omega \leqslant 0$ and $\mathrm{dTC}_{1} \leqslant 0 . \mathrm{TC}_{1}$ is, therefore, decreasing, and $p^{*}$ equals the upper bound of $\left[\mu P_{1}, P_{1}\right]$, or $P_{1}$.

2. $r R_{2}-4 k \omega>0 \rightarrow$ Solving for $\mathrm{dTC}_{1}$ and $p *=$ $r R_{2} \pm \sqrt{r R_{2}\left(r R_{2}-4 k \omega\right)} / 2 k$. Let $\quad p^{* 1}=r R_{2}-$ $\sqrt{r R_{2}\left(r R_{2}-4 k \omega\right)} / 2 k \quad$ and $\quad p^{* 2}=r R_{2}+$ $\sqrt{r R_{2}\left(r R_{2}-4 k \omega\right)} / 2 k$.

Since $\mathrm{d}^{2} \mathrm{TC}_{1}\left(p^{* 1}\right) \geqslant 0$ and $\mathrm{d}^{2} \mathrm{TC}_{1}\left(p^{* 2}\right) \leqslant 0, \mathrm{TC}_{1}$ is convex at $p^{* 1}$ and concave at $p^{* 2}$. Mathematically, the minimum level of $\mathrm{TC}_{1}$ is determined by the relations among $p^{* 1}, p^{* 2}, \mu P_{1}$, and $P_{1}$. There are a total of six possible relations: $p^{* 1} \geqslant P_{1}, \mu P_{1}<\cap$ $p^{* 1}<P_{1} \leqslant p^{* 2}, \quad \mu P_{1}<p^{* 1}<p^{* 2} \leqslant P_{1}, \quad p^{* 1}<\mu-$ $P_{1}<P_{1} \leqslant p^{* 2}, p^{* 1}<\mu P_{1}<p^{* 2} \leqslant P_{1}, p^{* 1}<p^{* 2}<\mu P_{1} \leqslant$ $P_{1}$. Fig. 5 displays the location of the optimal solution in these six possible cases. In any case, the optimal solution or the lowest $\mathrm{TC}_{1}$ level is located between the boundaries of $p^{* 1}=\mathrm{P}_{1}$ and $p^{* 1}=\mu P_{1}$. (Note that $p^{* 1} \leqslant p^{* 2}$.) Since this study is interested in investigating the effect of project characteristics (defined by $r$ (or $s$ ), $R_{2}$, and $k$ ), $P_{1}$ and $\mu P_{1}$ are rearranged as follows:

$p^{* 1}=\frac{r R_{2}-\sqrt{r R_{2}\left(r R_{2}-4 k \omega\right)}}{2 k}=P_{1} \Rightarrow \frac{r R_{2}}{k}=\frac{P_{1}^{2}}{P_{1}-\omega}$,

$p^{* 1}=\frac{r R_{2}-\sqrt{r R_{2}\left(r R_{2}-4 k \omega\right)}}{2 k}=\mu P_{1} \Rightarrow \frac{r R_{2}}{k}=\frac{\mu^{2} P_{1}^{2}}{\mu P_{1}-\omega}$.

Using Eqs. (A1) and (A2), we can then generate various combinations of $r R_{2} / k$ and $\omega$, given a 


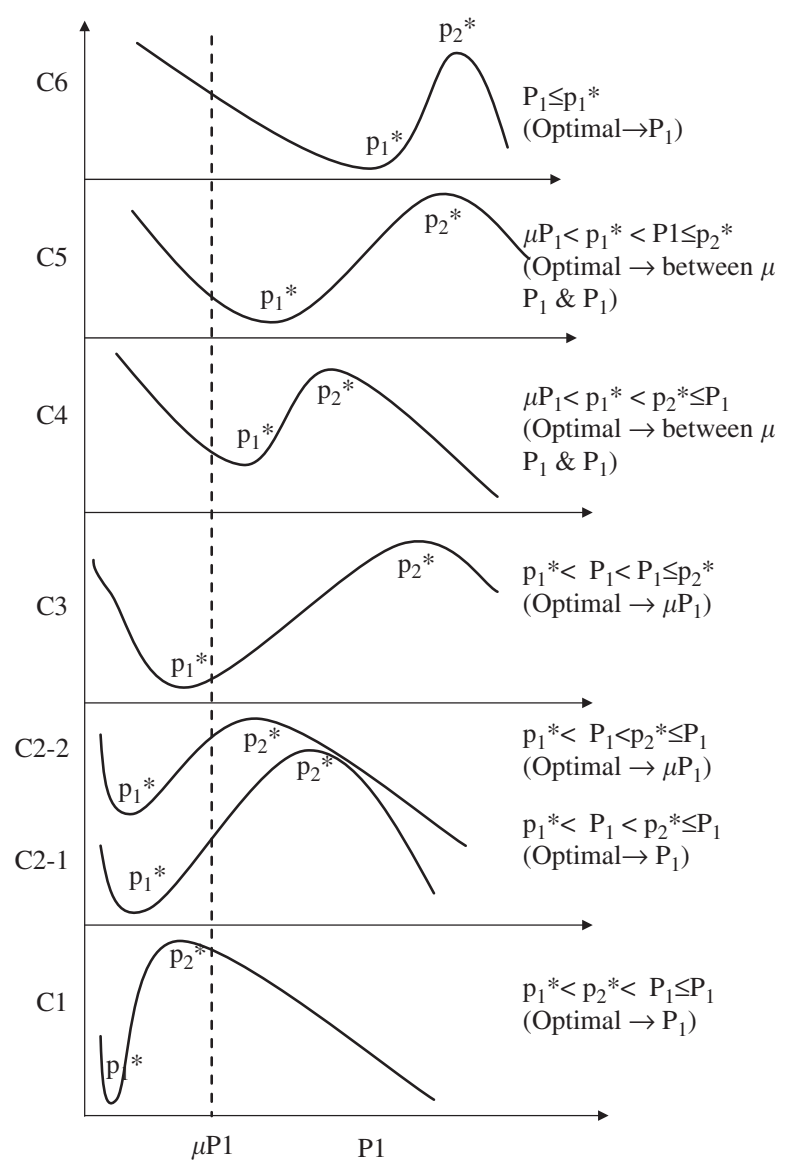

Fig. 5. Six possible locations of the optimal solution of $\mathrm{TC}_{1}$.

specific $P_{1}$ value. Accordingly, we can develop the pattern of risk-handling strategy selection as displayed in Fig. 4, where $r R_{2} / k$ and $\omega$ are treated as vertical and horizontal axes, respectively.

\section{A.2. Optimization analysis for $T C_{2}$}

Substitute $l=R_{2} / p$ to Eq. (9) and

$\mathrm{TC}_{2}=k \ln \left(\frac{P_{1}-\omega}{p-\omega}\right)+\frac{s}{\beta}\left(\mathrm{e}^{-\beta R_{2} / p}-\mathrm{e}^{-\beta L_{1}}\right)$

$\mathrm{dTC}_{2}=\frac{-k}{p-\omega}+\frac{s R_{2}}{p^{2}} \mathrm{e}^{-\beta R_{2} / p}$.

We can simulate the values of parameters in $\mathrm{TC}_{2}$ and derive the following findings.

1. When $\beta \sim 0$,

$$
\begin{aligned}
\mathrm{TC}_{2} & =\lim _{\beta \rightarrow 0}\left[k \ln \left(\frac{P_{1}-\omega}{p-\omega}\right)+\frac{s}{\beta}\left(\mathrm{e}^{-\beta R_{2} / p}-\mathrm{e}^{-\beta L_{1}}\right)\right] \\
& =k \ln \left(\frac{P_{1}-\omega}{p-\omega}\right)+\lim _{\beta \rightarrow 0}\left[\frac{s}{\beta}\left(\mathrm{e}^{-\beta R_{2} / p}-\mathrm{e}^{-\beta L_{1}}\right)\right] .
\end{aligned}
$$

Since $\lim _{\beta \rightarrow 0}\left[\frac{s}{\beta}\left(\mathrm{e}^{-\beta R_{2} / p}-\mathrm{e}^{-\beta L_{1}}\right)\right]=s\left(L_{1}-\frac{R_{2}}{p}\right)$,

$\mathrm{TC}_{2}=k \ln \left(\frac{P_{1}-\omega}{p-\omega}\right)+s\left(L_{1}-\frac{R_{2}}{p}\right)$.

Other than replacing $r$ by $s$, this cost function is the same as $\mathrm{TC}_{1}$ in Section A.1 of Appendix A. Therefore, the result of the optimality analysis for $\mathrm{TC}_{2}$ will be the same as $\mathrm{TC}_{1}$.

2. When $\beta>0$, the optimal value approaches $P_{1}$. The implication is that adaptation strategy is preferred when there is a high level of organizational slack available.

\section{References}

Ala-Risku, T., Karakkainen, M., 2006. Material delivery problems in construction projects: A possible solution. International Journal of Production Economics 104 (1), 19-29.

Al-Tabtabai, H., Alex, A.P., 2000. Modeling the cost of political risk in international construction projects. Project Management Journal 31 (3), 4-13.

Anderson, R.M., 1969. Handling risk in defense contracting, Harvard Business Review, July-August, pp. 90-98.

Baillie, S.A., 1980. Management of risk and uncertainty. Research Management, March 20-24.

Baumol, W.J., 1977. Economic Theory and Operations Analysis, fourth ed. Prentice-Hall, Englewood, NJ.

Becker, S., Ponniah, D., Smith, S., 1999. Risk response techniques employed currently for major projects. Construction Management and Economics 17, 205-213.

Bourgeois, L.J., 1981. On the measurement of organizational slack. Academy of Management Review 6 (1), 29-39.

Bromiley, P., Curley, S.P., 1992. Individual differences in risk taking. In: Yates, J.F. (Ed.), Risk-Taking Behavior. Wiley, New York, pp. 87-121.

de Vonder, S.V., Demeulemeester, E., Herroelen, W., Leus, R., 2005. The use of buffers in project management. International Journal of Production Economics 97 (2), 227-240.

DSMC, 1986. Risk Management-Concept and Guidance. DSMC Press, Virginia.

Fan, M., Lin, N.P., Sheu, C., 2001. Risk management in large scale projects. In: Proceedings of 2001 International Decision Sciences Institute Meeting. Chihuahua, Mexico.

Fan, M., Lin, N.P., Sheu, C., 2006. Risk response strategy in large-scale construction projects. Proceedings of 2006 Decision Sciences Institute Meeting. San Antonio, November.

Flanagan, R., Norman, G., 1993. Risk Management and Construction. Blackwell, Oxford, UK.

Gray, C.F., Larson, E.W., 2005. Project Management: The Management Process, third ed. McGraw-Hill, New York.

Holloway, C.A., 1979. Decision Making under Uncertainty. Prentice-Hall, Englewood Cliffs, NJ.

Jaafari, A., 2001. Management of risks, uncertainties and opportunities on projects: Time for a fundamental shift. International Journal of Project Management 19, 89-101. 
Kerzner, H., 2006. Project Management: A System Approach to Planning, Scheduling, and Controlling, ninth ed. Wiley, New York.

Kwak, Y.H., Stoddard, J., 2004. Project risk management: Lessons learned from software development environment. Technovation 24 (11), 915-920.

Lefley, F., 1997. Approaches to risk and uncertainty in the appraisal of new technology capital projects. International Journal of Production Economics 53 (1), 21-33.

March, J.G., Shapira, Z., 1987. Managerial perspectives on risk and risk taking. Management Science 33, 1404-1418.

Miller, R., Lessard, D., 2001. Understanding and managing risks in large engineering projects. International Journal of Project Management 19, 437-443.

Pender, S., 2001. Managing incomplete knowledge: Why risk management is no sufficient. International Journal of Project Management 19, 79-87.

Project Management Institute, 2004. Project Management Body of Knowledge. PMI Press, Newtown Square, PA.
Royer, P.S., 2000. Risk management: The undiscovered dimension of project management. Project Management Journal 31 (1), 6-13.

Shapira, G.J., 1998. Risk Taking: A Managerial Perspective. Russell Sage Foundation, New York.

Stewart, R.W., Fortune, J.J., 1995. Application of system thinking to the identification, avoidance and prevention of risk. International Journal of Project Management 13 (5), 279-286.

Stigler, D., 1961. The economics of information. Journal of Political Economy 59 (3), 213-225.

Tsai, T., 1992. Risk identification in major weapon systems acquisition in the Republic of China Air Force. Unpublished Master's Degree Thesis of Air University, OH, USA.

Wehrung, D.A., Lee, K., Tse, D.K., Vertinsky, I.B., 1988. Adjusting risky situations: A theoretical framework and empirical test. Journal of Risk and Uncertainty 2, 189-212.

Zahir, I., Sharif, A., Love, P., Kahraman, C., 2002. Applying concepts of fuzzy cognitive mapping to model: The IT/IS investment evaluation process. International Journal of Production Economics 75 (1/2), 199-211. 